\title{
Spontaneous apoptosis, oxidative status and immunophenotype markers in blood lymphocytes of AIDS patients
}

\author{
Gabriele A. Losa * and Riccardo Graber \\ Laboratorio di Patologia Cellulare, Istituto Cantonale \\ di Patologia, CH-6601 Locarno, Switzerland
}

Received 14 March 2000

Accepted 25 July 2000

Peripheral blood mononuclear cells (PBMC) from 251 HIVpositive drug abusers of known clinical stage and from 40 healthy donors were tested for conventional immunologic markers (CD3, CD4, CD8, CD19, CD14, CD16/CD56, CD45 and HLA-DR). Additional cell parameters and the occurrence of spontaneous apoptosis (programmed cell death) were investigated on freshly isolated PBMC by flow cytometric measurement of either annexin- $\mathrm{V}$ bound to plasma membrane phosphatidylserine or propidium iodide uptake. The activity of $\gamma$-glutamyltransferase $(\gamma-\mathrm{GT})$, an ectoenzyme contributing to the synthesis of the intracellular antioxidant glutathione (GSH) and involved in early apoptosis, was also determined in these cells. Immunocompetent T-cell counts were lower in HIV+ patients, with the exception of CD8+ and HLA-DR+ lymphocytes. The external binding of annexin- $\mathrm{V}$ was significantly higher in HIV+ PBMC and occurred in both CD8+ and CD4+ T-lymphocyte subsets. The activity of $\gamma$-GT, was significantly lower in the PBMC from $\mathrm{HIV}+$ patients, indicating that the redox status of PBMC may be affected in HIV+ individuals. Finally, the most dominant features characterising patients receiving antiretroviral therapy were greater long-term stability in the distribution of various cell parameters excepted the level of apoptosis.

Keywords: Apoptosis, AIDS, HIV stages A, B and C, blood lymphocytes, $\mathrm{CD}, \gamma$-glutamyltransferase, glutathione (GSH), surface markers, annexin-V/phosphatidylserine, flow cytometry

\footnotetext{
*Corresponding author: Gabriele A. Losa, Laboratorio di Patologia Cellulare, Istituto di Patologia, Via In Selva 24, CH-6601 Locarno, Switzerland. Tel.: +41 091756 2680; Fax: +41 091756 2691; E-mail: glosa@guest.cscs.ch.
}

\section{Introduction}

Functional, morphologic and structural differences in mononuclear cells, including the $\mathrm{T} / \mathrm{B} / \mathrm{NK}$ subsets and monocytes, in healthy subjects and HIV+/AIDS patients have been consistently reported for some time $[23,25,27]$. But the cytoplasmic metabolic processes [1] in immunocompetent PBM cells have received less detailed investigation, apart from the purine and pyrimidine enzymatic and metabolic pathways $[33,34,44]$, and most of these studies have concerned the cell surface, mitochondria and nuclear organelles $[13,24,32,38]$. The antioxidant status and redox related pathways have recently received increased attention, since it has been suggested that oxidative stress could be implicated in several aspects of the pathogenesis of HIV disease, including viral replication, inflammatory response, decreased immune cell proliferation, loss of immune function and apoptotic cell death [35]. Pro-oxidant conditions resulting from the excessive production of reactive oxygen forms, combined with a multilevel deficiency of nutritional and metabolic sources of antioxidants, have been suggested as possible triggers of programmed cell death [18]. It has also been suggested that low levels of antioxidants (vitamin E, selenium, glutathione, Mn-dismutase) arising from inappropriate diet, or alcohol or drug consumption, could induce CD4+ T-cell apoptosis in AIDS patients [43]. The production of reactive oxygen intermediates [22], together with a decreased level of protective agents [41], in particular of glutathione [47] have been found to be associated with an increased rate of apoptosis leading to depletion of the CD4+ T-cell subset. Depletion of the intracellular antioxidant glutathione (GSH) is a major feature of oxidative stress in PBMC of HIV+ patients [21,41,42,47]. It can be counteracted by thiol-containing antioxidants, such as N-acetyl-L-cysteine, which increase the survival of CD4+ lymphocytes and inhibit programmed 
cell death [7,10,29,42]. However, some authors have reported no intracellular GSH deficiency in PBMC from HIV+ patients [40] or even a higher total GSH level in CD4+ lymphocytes from HIV+ patients than in those from healthy subjets [48]. It has been shown that HIV-induced apoptosis of T-cells is preceded by an exponential increase in the reactive oxygen intermediates (ROIs) produced in mitochondria. This leads not only to GSH depletion, but also to caspase-3 activation and phosphatidylserine externalization on the outer leaflet of the plasma membrane, characteristic hallmarks of active apoptotic cell death [3]. Almost all the studies suggest that oxidative damage and cell death contribute to the decline of CD4 lymphocytes which occurs during the course of HIV infection, although the possible link between these two processes remains to be elucidated [20]. The difficulty of unravelling these aspects is illustrated by the functional complexity of the GSH metabolic system which must be coordinated through specific enzymes, such as the gamma-glutamyltransferase ( $\gamma-\mathrm{GT})$, which may be either soluble or membrane-bound [46]. This antioxidant enzyme has been shown to be rapidly activated in human lymphoid cells during the early phases of apoptosis induced by the glucocorticoid dexamethasone [17] or by the oxidant deoxyribose [16]. During the late phases of programmed cell death induced by this oxidant, the $\gamma$-GT activity was highly inhibited [16]. The present study was designed to determine the apoptosis rate in peripheral blood mononuclear cells from HIV+ patients and to relate this to the $\gamma$ GT-dependent intracellular GSH metabolism involved in protecting the cells against the oxidative stress associated with immune deficiency. The apoptosis rate and relative distribution of the various lymphocyte subsets have been investigated as a function of the clinical status of the disease and monitored during antiretrovirus therapy.

\section{Methods}

\subsection{Materials}

Monoclonal antibodies (Simultest ${ }^{\mathrm{TM}}-\mathrm{IMK}$ ) were purchased from Becton-Dickinson, Basel, Switzerland. Ficoll-Hypaque was from Fakola AG, Basel, Switzerland. All other reagents used for the various assays were purchased from Sigma AG, Buchs, Switzerland.

\subsection{Patients and healthy blood donors}

Several cell parameters, detailed below, were repeatedly determined at regular intervals (followed-up for 60-72 months) in $\mathrm{K}_{3}$-EDTA-blood samples within 2 hours of venipuncture. The study included 251 $\mathrm{HIV}+$ patients with intravenous drug abuse and a total of 1573 determinations were obtained. The gender composition of the HIV patients was $59 \%$ men and $41 \%$ women, with ages ranging from 15 to 68 years. $38 \%, 34 \%$ and $28 \%$ were at clinical stages A (asymptomatic), B (with minor opportunistic infections), and C (with AIDS defining conditions), respectively, when they first presented. There were 40 healthy donors (55\% men and $45 \%$ women) with ages ranging from 19 to 56 years. The patients were treated according to the protocol established by physicians of the Servizio Malattie Infettive, Ospedale Civico, Lugano, Switzerland. Their treatment consisted of either (i) nucleoside inhibitors of reverse transcriptase, (ii) non-nucleoside inhibitors of reverse transcriptase or (iii) inhibitors of viral protease. Cell parameters were followed before and during antiviral therapy (started on June 1996) in five out of 251 HIVinfected patients, defined at the first presentation as follows: patient I, stage A and patients II, III, IV, V, stage B. Patient I was treated with Indinavir/d4T up to February '97; AZT/Indinavir/3TC up to December ' 98 and then with Abacavir/Efavirenz/Nelfinavir. Patient II was treated with Indinavir/AZT/3TC up to April '97; with Ritonavir/Invirase/d4T up to October '98 and then with Saquinavir/Abacavir/d4T/Efavirenz. Patient III was treated with Indinavir/AZT/3TC. Patient IV was treated with Indinavir/ddI/d4T. Patient V was treated with AZT/3TC. The time course of cell parameters for patient III alone (stage B) has been reported in Fig. 3.

\subsection{Lymphocyte immunophenotype}

Immunophenotype lymphocyte subsets were assessed after lysis of whole blood by staining with the Simultest ${ }^{\mathrm{TM}}$ IMK from Becton-Dickinson, a two-color direct immunofluorescence kit for counting leukocytes (CD45-FITC), T lymphocytes (CD3-FITC), helper/inducer T lymphocytes (CD3-FITC/CD4-PE), suppressor/cytotoxic $\mathrm{T}$ lymphocytes (CD3-FITC/CD8-PE), natural killer $\mathrm{T}$ lymphocytes (CD3-FITC/CD16+ CD56-PE), B lymphocytes (CD3-FITC/CD19-PE) and monocytes (CD45-FITC/CD14-PE). HLA-DR T-lymphocytes were stained with CD3-FITC/DR-PE antibodies from Becton-Dickinson. All PBMC stained subpopulations were analyzed using a FACscan flow cytometer equipped with Simulset software. Absolute lymphocyte counts were performed by Trucount ${ }^{\mathrm{TM}} \mathrm{ab}-$ solute counting procedure from Becton-Dickinson. 


\subsection{Isolation of the peripheral blood mononuclear cells}

PBM cells were isolated from blood samples on a Ficoll-Hypaque gradient, by the usual method [16], washed twice with $\mathrm{NaCl} 0.9 \%, \mathrm{pH} 7.4$, and counted using a Neubauer chamber. PBMC viability, determined by trypan blue exclusion, was always greater than $95 \%$.

Cell homogenates were obtained by homogenizing the cell suspensions in $\mathrm{NaCl} 0.9 \%$ at $\mathrm{pH} 7.4$ (10 strokes up and down at $4000 \mathrm{rpm}$ ) and used for enzyme activity determinations, providing optimization for duration, $\mathrm{pH}$, protein and substrate concentration.

\subsection{Assay of $\gamma$-glutamyltransferase}

$\gamma$-Glutamyltransferase ( $\gamma$-GT; EC 2.3.2.2) was assayed by incubating homogenates of PBMC (50 $\mu \mathrm{g}$ protein) in $1 \mathrm{ml}$ of a reaction mixture containing $20 \mathrm{mM}$ Tris- $\mathrm{HCl}$ buffer $\mathrm{pH}$ 8.0, $60 \mathrm{mM}$ glycylglycine, $300 \mathrm{mM} \mathrm{NaCl}$ and $2.5 \mathrm{mM} \gamma$-glutamyl-p-nitroanilide. The reaction was terminated by adding $2 \mathrm{ml} 1.5 \mathrm{~N}$ acetic acid. The mixture was cleared by centrifuging $\left(800 \times g, 20 \mathrm{~min}\right.$ at $\left.4^{\circ} \mathrm{C}\right)$ and the absorbance of the p-nitroaniline in the supernatant was measured at $410 \mathrm{~nm}$ using a Beckman DU-65 spectrophotometer. The enzyme activity was expressed in $\mathrm{nmol} / \mathrm{min} / \mathrm{mg}$ protein [16].

\subsection{Characterization of apoptosis}

\subsubsection{Annexin- $V$ binding}

Annexin- $\mathrm{V}$ is an adhesion molecule which, in presence of $\mathrm{Ca}^{2+}$, is tightly bound to the phosphatidylserine exposed on the outer membrane leaflet of mononuclear cells undergoing apoptosis [30]. Annexin-VFITC was diluted 10-fold with binding buffer containing $\mathrm{CaCl}_{2}$. Five $\mu \mathrm{l}$ of diluted annexin-V-FITC were incubated with $50 \mu \mathrm{l}$ of whole blood for $20 \mathrm{~min}$ at room temperature. After lysing with Becton-Dickinson lysis buffer, the white blood cells were washed twice and analyzed using a FACscan flow cytometer equipped with Simulset software. Each final assay sample contained $24.5 \mathrm{mM} \mathrm{CaCl} 2$. This value was determined from the dose/response curve for whole blood from healthy donors for $\mathrm{CaCl}_{2}$ concentrations ranging from 0.4 to $30 \mathrm{mM}$. At $24.5 \mathrm{mM} \mathrm{CaCl} 2$, two main conditions were fulfilled: firstly, the binding of annexinV-FITC to white blood cells was found to be optimal, and secondly, no any coagulation occurred. This was because the anticoagulant action of the calcium- chelating $\mathrm{K}_{3}$-EDTA ( $5 \mathrm{mM}$ ) added to the blood sample was preserved. This is probably attributable to a salting-out like process that inactivates the serum proteins involved in coagulation.

\subsubsection{Permeability of cell plasma membrane to propidium iodide $(P I)$}

The permeability was measured by flow cytometry on isolated PBMC as described by Graber et al. [6, 16]. It has been shown that cells which have a plasma membrane with an intact lipid bilayer successfully exclude lipophilic dyes, such as PI, whereas cells in which the membrane structure has been breached do not. Membrane permeability to PI is thought to be indicative of apoptotic cell death. Apoptotic cells display intermediate patterns of membrane permeability, resulting in variable dye uptake. Cells $\left(1 \times 10^{5}-10^{6}\right)$ from healthy donors and HIV-positive patients were collected by centrifuging on Ficoll-Hypaque gradients, resuspended in $0.5 \mathrm{ml} \mathrm{NaCl} 0.9 \%, \mathrm{pH} 7.4$ containing $5 \mu \mathrm{g} / \mathrm{ml} \mathrm{PI}$, incubated for $7 \mathrm{~min}$ at room temperature and washed with $\mathrm{NaCl}$. Histograms of the cell subpopulations were obtained using a FACscan (BectonDickinson) equipped with Lysis II software, which was able to distinguish three main fluorescence peaks, corresponding to cells with low, intermediate and high levels of permeability.

\subsection{Statistics}

None of the immunologic and cell parameters measured in PBMC isolated from HIV patients $(N=251)$ and from normal donors followed a normal (Gaussian) distribution, and so median values were determined to provide reliable descriptors of different groups of probands, namely PBMC from $\mathrm{HIV}+$ patients (at clinical stages A, B and C) and from healthy donors. The data were analysed using non-parametric statistics, including the Kruskall-Wallis and Mann-Whitney $U$ tests. The Spearman correlation coefficient test was used to carry out the statistical analysis of correlations.

\section{Results}

The data reported in Table 1 and in Fig. 1a show that the median values of CD45-leukocytes, and CD3-T, CD4-T, CD19-B and CD16/56-NK lymphocyte subpopulations were significantly lower $(p<0.001)$ in HIV patients than in normal donors. CD14-monocytes were slightly lower $(p=0.05)$, and the CD8-T subset were the same in these two groups. HLA-DR 
Table 1

Range of values (cells $/ \mu \mathrm{l}$ ) and median values \pm standard error on the median (SEM) testing positive for CD45, CD14, CD3, CD8, CD4, CD16/56, CD19, HLA-DR, annexin-V and $\gamma$-GT activity (nmol/min/mg) in PBMC from healthy donors and HIV+ intravenous drug abusers

\begin{tabular}{|c|c|c|c|c|c|c|c|c|c|c|c|}
\hline & & CD45 & CD14 & CD3 & CD3/CD8 & $\mathrm{CD} 3 / \mathrm{CD} 4$ & CD16/56 & CD19 & HLA-DR & Annexin-V & \multirow{2}{*}{$\begin{array}{c}\gamma-\mathrm{GT} \\
\mathrm{nmol} / \\
\mathrm{min} / \mathrm{mg}\end{array}$} \\
\hline & & \multicolumn{9}{|c|}{ cells/ $\mu 1$} & \\
\hline Healthy & range & $828-3320$ & $18-1008$ & $322-2566$ & 149-2202 & $265-1870$ & $59-630$ & $83-730$ & $30-472$ & $8-355$ & $3.1-28.6$ \\
\hline donors & $\begin{array}{c}\text { median } \pm \\
\text { SEM }\end{array}$ & $1885 \pm 944$ & $300 \pm 150$ & $1425 \pm 771$ & $599 \pm 354$ & $873 \pm 372$ & $200 \pm 78$ & $200 \pm 90$ & $125 \pm 69$ & $65 \pm 8$ & $23.1 \pm 4$ \\
\hline HIV & range & $40-6400$ & $0-1740$ & $10-4920$ & $3-4500$ & $0-2110$ & $0-1020$ & $0-1128$ & $0-2870$ & $0-1631$ & $0-25.9$ \\
\hline & $\begin{array}{c}\text { median } \pm \\
\text { SEM }\end{array}$ & $1292 \pm 180$ & $252 \pm 17$ & $941 \pm 60$ & $690 \pm 50$ & $220 \pm 10$ & $110 \pm 8$ & $115 \pm 10$ & $313 \pm 20$ & $140 \pm 8$ & $7.25 \pm 2$ \\
\hline
\end{tabular}

was the only parameter measured which exhibited a significantly increased median level in HIV patients (Fig. 1a). The range of immunophenotype parameters measured was generally wider in HIV patients, due to the higher upper limits (Table 1). Significant differences were found in the surface profile parameters of PBMC from stage A, B and C HIV-groups, particularly between groups $\mathrm{A}$ and $\mathrm{B}$ and/or groups $\mathrm{A}$ and $\mathrm{C}$, rather than between groups $\mathrm{B}$ and $\mathrm{C}$. The absolute cell count (median value) of CD45, CD3, CD4 and CD8 lymphocytes and CD14 monocytes in groups $\mathrm{A} / \mathrm{B}$ and $\mathrm{A} / \mathrm{C}$ were most affected, whereas in groups $\mathrm{B}$ and $\mathrm{C}$, changes were restricted to the CD3-T, CD19$\mathrm{B}$ and CD16/CD56 lymphocytes (Fig. 1a). It is noteworthy that the CD16/CD56 subset value was similar in groups $\mathrm{A}$ and $\mathrm{C}$, but all the other immunological markers tended to decrease as the severity of the AIDS increased (stages A, B and C). Distinct functional parameters expressed at the lymphocyte surface were found to be significantly altered: there were more than twice as many cells positive for annexin- $\mathrm{V}$ bound to membrane phosphatidylserine $(p<0.01)$ in the whole HIV-PBMC population and the specific activity of the ectoenzyme $\gamma$-glutamyltransferase was one third $(p<0.01)$ (median value: $7.25 \pm 2.0 \mathrm{nmol} / \mathrm{min} / \mathrm{mg}$ ) that found for the PBMC of the control group (23.1 \pm $4.0 \mathrm{nmol} / \mathrm{min} / \mathrm{mg}$ ) (Table 1; Fig. 1b,c). There were no statistically significant differences (median values) between the three groups of patients for apoptosis as measured by annexin-V level, intermediate membrane PI permeability or by $\gamma$-glutamyltransferase activity (Fig. 1b-e). The distribution of cells with an intermediate degree of permeability to propidium iodide, paralleled the relative distribution of annexin- $\mathrm{V}$ positive cells (Fig. 1d) which in turn mirrored the absolute number of annexin-V positive cells (cells $/ \mu \mathrm{l}$ ) among the different groups (Fig. 1b). A positive correlation (Spearman rank correlation) could be estab- lished between the absolute numbers of annexin- $\mathrm{V}$ positive cells (cells/ $\mu \mathrm{l}$ ) and of CD3, CD8 and CD19 lymphocytes, but unexpectedly not with the CD4 lymphocyte subpopulation (Fig. 2). The clinical significance of recording lymphocyte subsets was inferred from analyzing experimental data collected from five HIV-infected patients during extended follow up (minimum 36 months) before and during antivirus therapy, as illustrated for a single patient (patient III). Figure 3a shows that the therapy, consisting of the cocktail of specific antiviral agents produced rather disparate effects on the various mononuclear cell populations. The CD3, CD4 and CD8-T subpopulations all displayed their own course of oscillations the amplitude of which was lower than before therapy. In contrast, the annexin- $\mathrm{V}$ positive lymphocytes continued to display widely oscillating values even under therapy, as indicated by the coefficients of variation (Fig. 3b). During therapy, the CV values for the CD3/CD4/CD8 T-lymphocyte subpopulations were less than $40 \%$, i.e., always less than before therapy, whereas the $\mathrm{CV}$ value for annexin- $\mathrm{V}$ positive cells remained at about $60 \%$ (Fig. 3b). Figure $3 \mathrm{c}$ reveals that mean and median values of specific lymphocyte subpopulations were modified after therapy. Cell values reported before and after therapy could not be described mathematically, because they did not asymptotically converge toward a steady baseline-level, although the amplitude of oscillations generally decreased during therapy.

\section{Discussion}

In this study we investigated the occurrence of spontaneous apoptosis in peripheral blood mononuclear cell (PBMC) subpopulations from HIV-infected patients as a function of the oxidative metabolism and the expression of the cell phenotype. With the exception of 
(a)

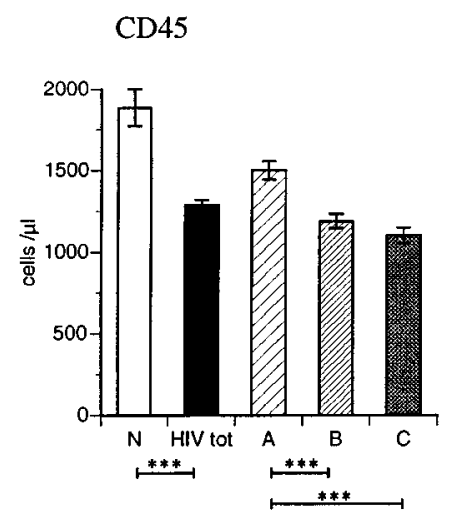

$\mathrm{CD} 3 / \mathrm{CD} 4$

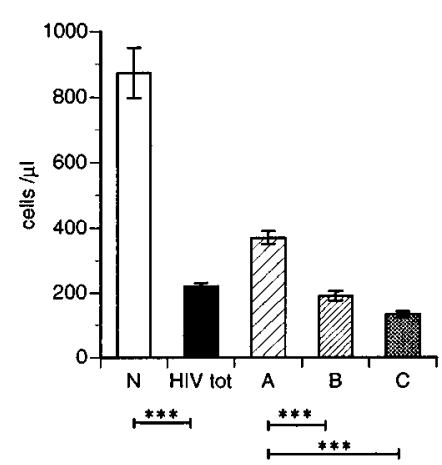

CD16/CD56

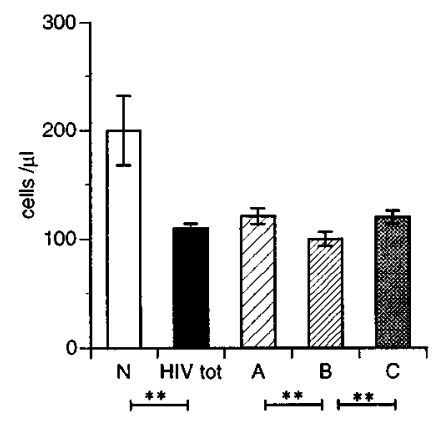

CD3

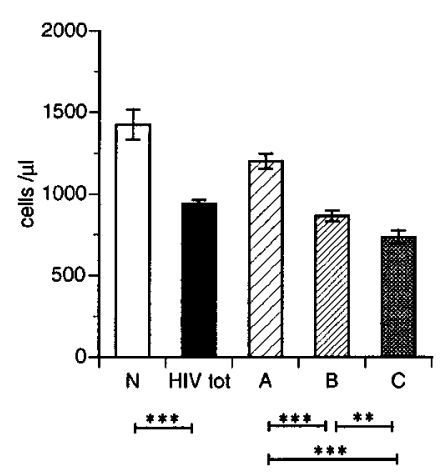

$\mathrm{CD} 3 / \mathrm{CD} 8$

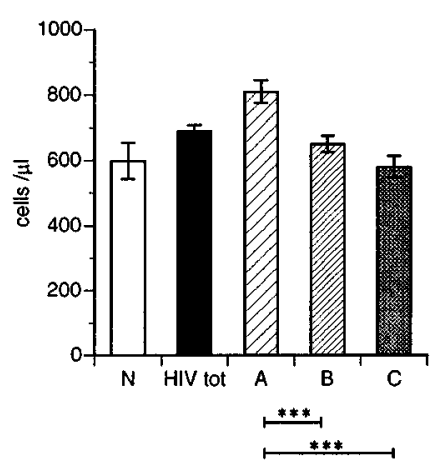

HLA-DR

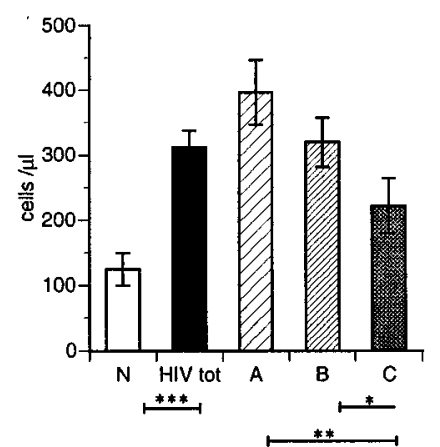

Fig. 1. Median values \pm one standard error on the median of immunological markers (a), and of annexin-V level, intermediate PI permeability and $\gamma$-GT activity (b,c,d,e) measured in PBMC isolated from healthy donors $(\mathrm{N})$, from the total HIV population (HIV tot), and from subclinical groups A, B and C. *; **; ***: significantly different $(p<0.05 ; p<0.01$ and $p<0.001$, respectively).

Continued on next page. 
(b) Annexin-V

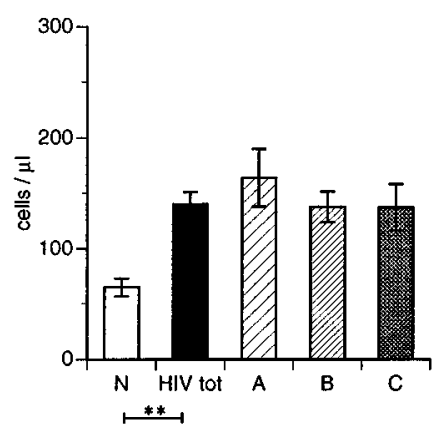

(d) Annexin-V

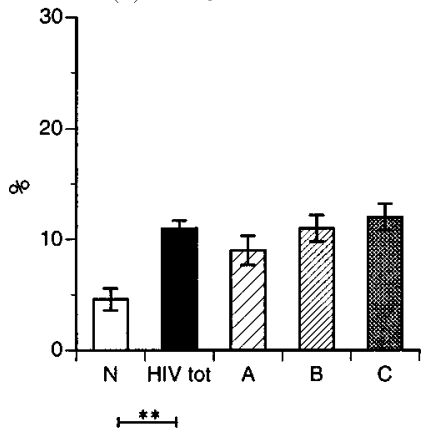

(c) $\gamma$-glutamyltransferase

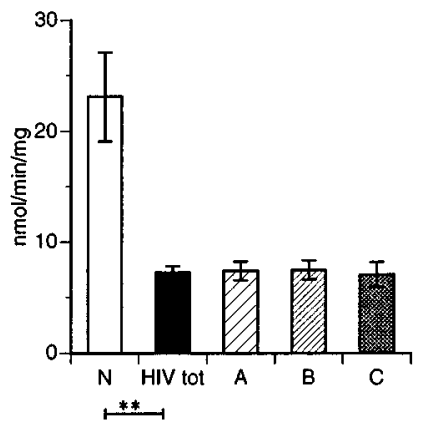

(e) Intermediate permeability

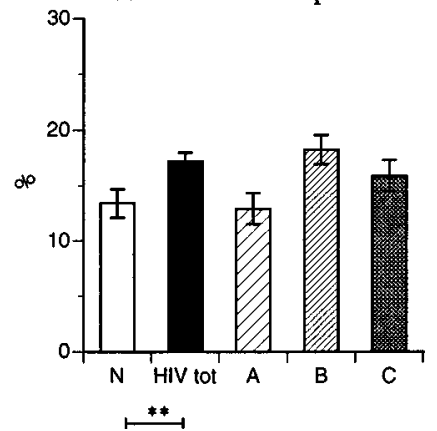

Fig. 1. (Continued.)

suppressor CD8 cells, all the mononuclear cell subsets, including CD4, CD19, CD14 and CD16+CD56 were found to be lower than those of freshly isolated PBMC from healthy individuals. The only cells showing a marked increase were the HLA-DR activated T-cells (300 vs 120 cells/ $\mu \mathrm{l})$ and cells bearing apoptotic markers (140 vs 65 annexin-V positive cells $/ \mu \mathrm{l}$ ) which were increased twofold in these HIV blood samples. Previous studies have reported that lymphocytes from HIV-infected subjects have a low apoptosis rate $(<5 \%)$, similar to that of PBMCs from healthy individuals $[14,15]$. Our investigation revealed that the frequency of spontaneous apoptosis, measured either by annexin- $\mathrm{V}$ binding or PI permeability, was similarly increased in the three major clinical subgroups of HIV patients (corresponding to clinical stages A, $\mathrm{B}$ and $\mathrm{C}$ ). In contrast, all the other immunophenotypic parameters measured were significantly different in the different groups, but the highest values were found in the asymptomatic group A. It has already been shown that immune-activated (CD38+) CD8 lymphocytes were cells committed to apoptosis in HIVinfected patients [20,28]. An increase in the number of apoptotic CD3+ T-cells was observed which paralleled that of HLA-activated cells [14]. The data for the lymphocyte subsets committed to apoptosis displayed some discrepancies. On the one hand, some data have been reported showing that more than $80 \%$ of circulating CD4+ T-cells from asymptomatic, HIV-infected individuals were apoptotic [1]. On the other hand, a correlation was observed between apoptosis of both CD4+ and CD8+ T-cells with CD4+ T-cell depletion in HIV-infected children and adults [9]. Most studies have revealed that apoptosis, whether occurring spontaneously or induced in vitro, affects the CD4+ T-cell subset to the greatest extent and is the main cause of depletion of this subset in HIV+ patients [12,15,36,50], whereas B-cells are only involved in a few cases $[6,45]$. A single study seemed to show that apoptosis was also enhanced in CD8+ cells [5]. Studies of CD4-depletion in HIV patients, have shown that increased lymphocyte apoptosis is sometimes detected in long-term nonprogressor subgroups of HIV-infected patients prior to the decline in their CD4+ T-cell [19]. Recently, several authors have proposed that CD4-T-cell lymphopenia could be due to a failure in the replacement of $\mathrm{T}$ cells, including both the CD4 and CD8 subsets, and/or to a shorter survival time of the CD4 subset $[8,26,37]$ rather than a CD4 T-cell destruction [11]. The rate of CD4+ T-cell production is higher in treated HIV pa- 
a)

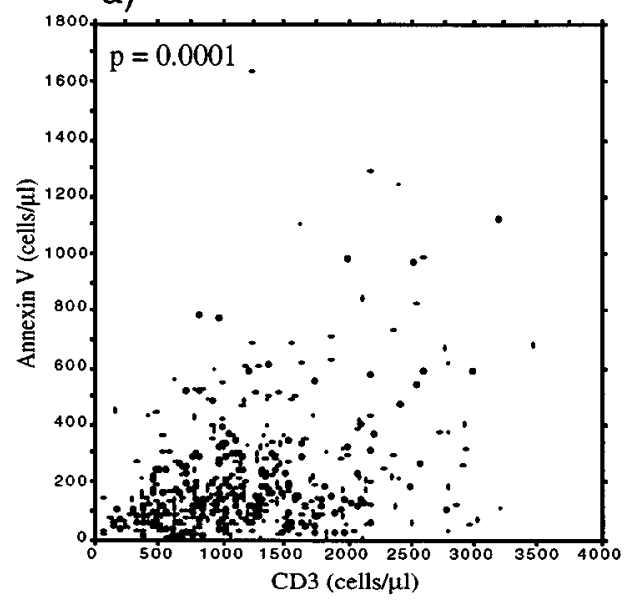

c)

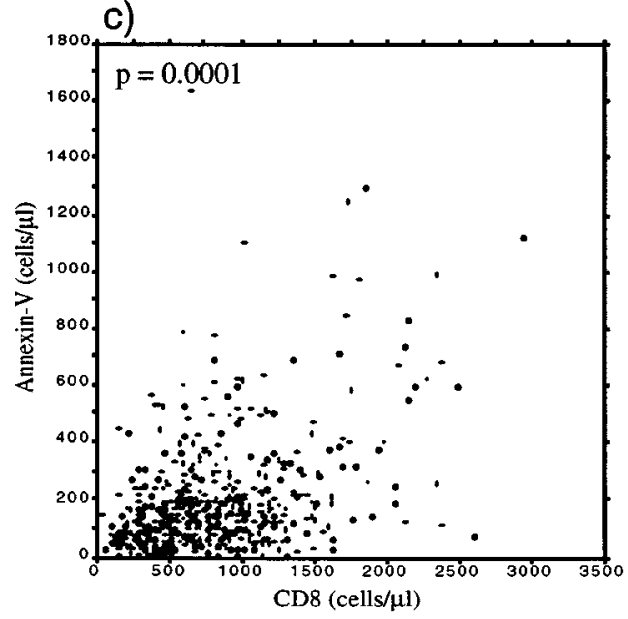

b)
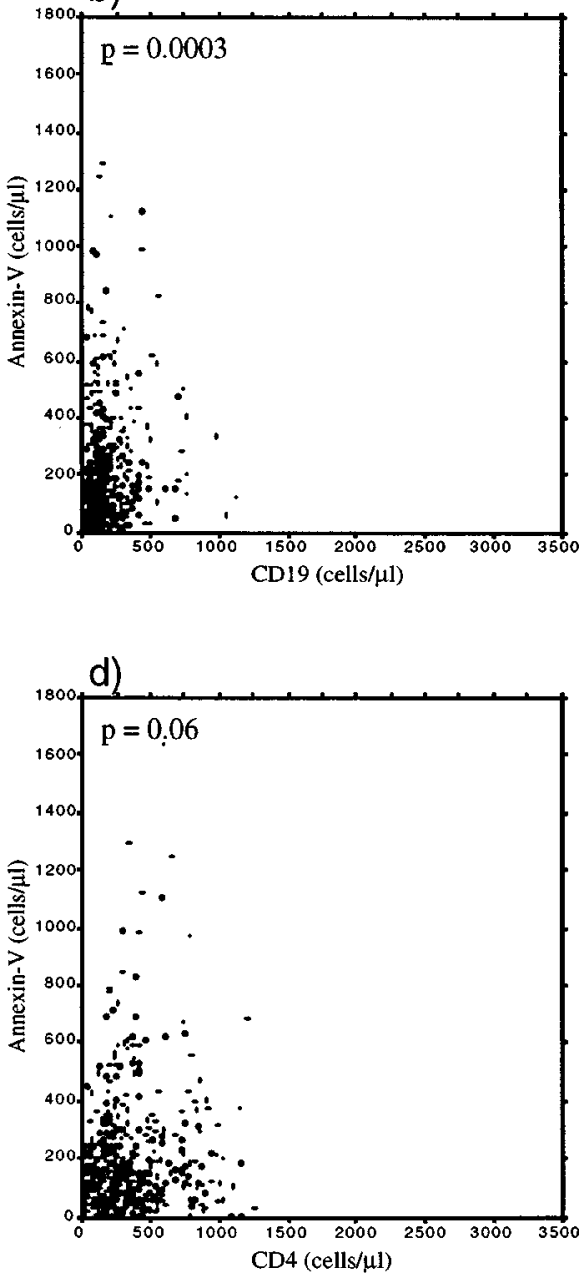

Fig. 2. Relationships between the annexin-V-positive cell count (cells/ $\mu \mathrm{l}$ ) and the absolute celll number (cells/ $\mu \mathrm{l})$ positive for CD3, CD19, CD8 and CD4 distinct subpopulations. The Spearman correlation significance $(p)$ is indicated on the top of each figure. The Spearman rank correlation coefficients $\left(r_{\mathrm{s}}\right)$ are: $0.31 ; 0.16 ; 0.35$; and 0.09 for the correlations plotted in (a) (b) (c) and (d), respectively. Only in plot (d) there was no significant correlation between CD4/A-V, as indicated by $p=0.06$.

tients than in controls and untreated patients, and this has led to the suggestion that antiviral therapy could disinhibit the T-cell production machinery [19]. Such claims are based on single or repeated determinations during a relative short period of treatment $[11,19]$. We took a different approach and monitored the expression of CD3, CD4, CD8 and CD19 subsets plus the apoptotic marker annexin- $\mathrm{V}$ in five $\mathrm{HIV}+$ patients undergoing antiviral therapy over a period of more than 30 months (Fig. 3 reports data from patient III only). Repeated flow-cytometric determinations revealed individual fluctuations of the various cell subsets, but the common pattern which emerged was the amplitude of these fluctuations was smaller than during the period without specific antiviral therapy. This was reflected by smaller coefficients of variation (CV). The outcome seemed to be fairly stable for each patient undergoing therapy. Coincidentally, the median values thought to be representative distribution descriptors of the cell parameters involved in the immune response were mostly unaffected. Overall, our findings tend to highlight that after a slight increase in the distinct T-cell subset and in the apoptotic process in the PBMC populations soon after antiviral therapy was started, it then has a regulatory effect on these circulating immune cells in the five patients examined. But even during therapy, the apoptotic cell level continued to vary widely, with $\mathrm{CV}>$ $60 \%$. The behavioural trend for each cell subpopula- 


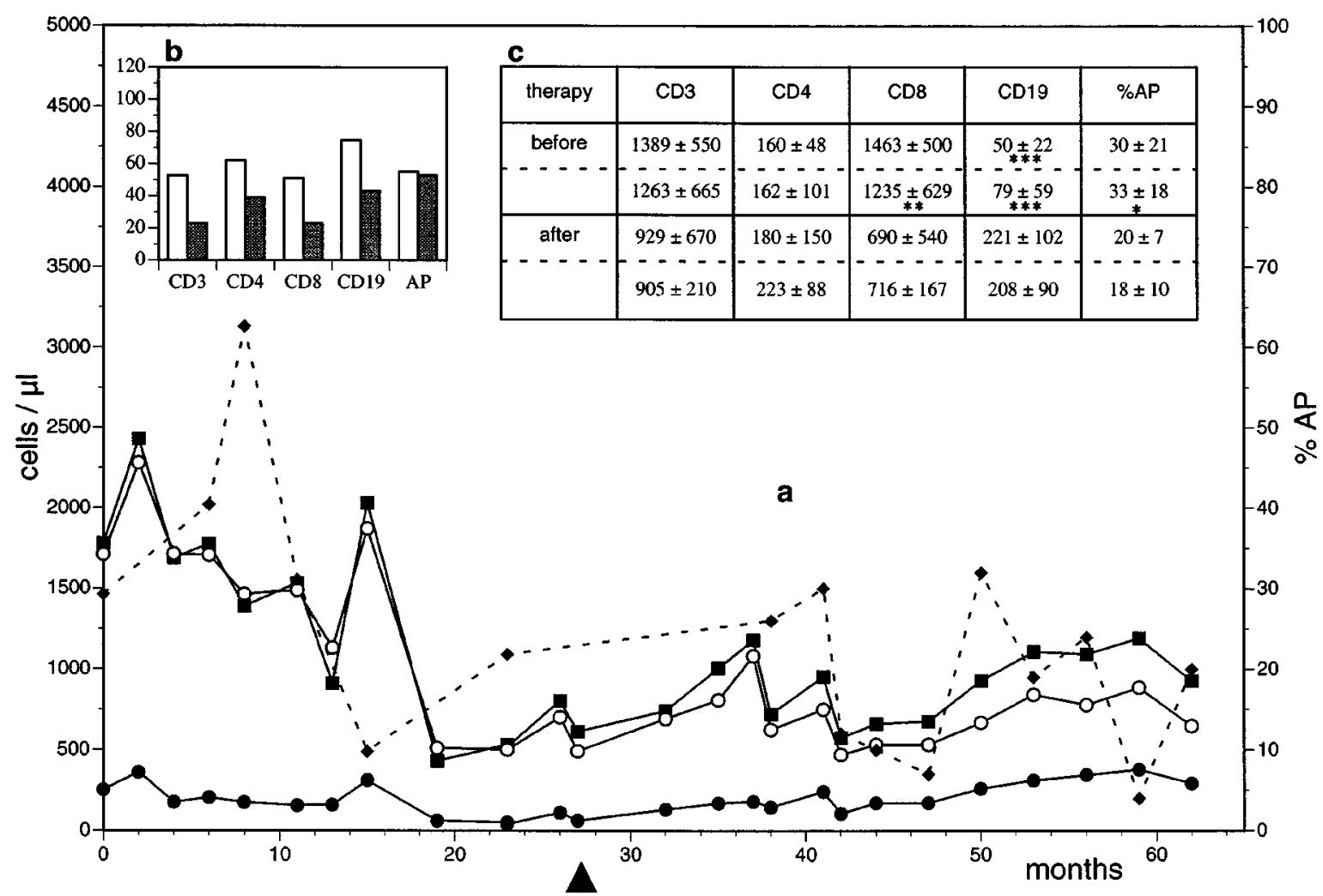

Fig. 3. Cell parameters before and during antiviral therapy for a single HIV-infected patient (stage B), representative of other four cases. Arrow

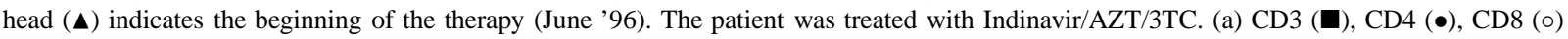
T-cell absolute counts (cells $/ \mu \mathrm{l})$ and percentage of annexin-V positive apoptotic cells (\% AP, $\$$ ). (b) Coefficient of variation (\% CV) before (white column) and after therapy (grey column) for CD3, CD4, CD8 and CD19 and \% of apoptotic cells (\% AP) in these lymphocyte populations. (c) Table summarizing median values \pm one standard error on the median (upper row) and mean values \pm one standard deviation (lower row) before and after therapy for the CD3, CD4, CD8 and CD19 counts and \% of apoptotic cells (\% AP) in these lymphocyte populations. $* ; * * * * *$ : significantly different before and after therapy $(p<0.05 ; p<0.01$ and $p<0.001$, respectively).

tion could not be assessed from our data, and the ultimate outcome of the therapy became unpredictable. The observation together with the experimental evidence that the CD4+ T-cell subset was not significantly reduced could suggest, in partial agreement with what was previously proposed $[11,19]$ that production of the entire T-cell population was maintained by the therapy. Other authors have presented evidence that antiretroviral therapy (10-12 weeks) increases the absolute lymphocyte and CD4 T-cell counts and decreases apoptosis in CD4 and CD8 T-lymphocytes [4,31]. Another study reported that early T-cell apoptosis did not decline during 8 weeks of antiretroviral therapy, and that about $30 \%$ of HIV+ patients displayed a marked decrease in T-cells with features of early apoptosis after 26 weeks of therapy [2]. We noticed a marked decrease of the $\gamma$-GT activity involved in recycling extracellular glutathione in the PBMC of HIV+ patients. This is further evidence of a perturbed redox potential and consequently an increased oxidative level. In this context, it has been observed that in normal human PBMC a soon increase of the $\gamma$-GT content occurred in response to induction of apoptosis and oxidative injuries by deoxyribose. These cells were pre-apoptotic at this stage but under prolonged deoxyribose exposure they underwent irreversible apoptosis and simultaneously displayed marked inhibition of $\gamma$-GT activity and depletion of intracellular GSH [16]. At the opposite, human lymphoid CEM cells responded to the glucocorticoid stress by inducing both $\gamma$-GT and apoptosis [17]. Some authors had previously reported that the oxidative stress associated with HIV infection induced GSH depletion and the increased production of free radicals and/or reactive oxygen intermediates, and was reponsable for the induction of apoptosis in the whole lymphocyte population $[3,10,39,42,49]$. Others identified CD4 lymphocytes as preferential targets for cell death during oxidative stress $[22,29,43]$. Whichever cell sub- 
set is involved in apoptosis, it could be well worth to examine the effect of antioxidant agents on lymphocyte antioxidative defenses from AIDS patients.

\section{Aknowledgements}

This study was supported by grant No. 31-45779.95 from the Swiss National Science Foundation. The medical collaboration of Dr. Enos Bernasconi, Servizio di Malattie Infettive, Ospedale Civico CH-6900 Lugano, Switzerland was highly appreciated. The skilful technical assistance of Mrs. Antonella Camponovo and Morena Ghisletta is aknowledged. We thank also Dr. Owen Parkes (Paris) for editorial help.

\section{References}

[1] G. Amendola, M.L. Gougeon, F. Poccia, A. Bondurand, L. Fesus and M. Piacentini, Induction of "tissue" transglutaminase in HIV pathogenesis: evidence for high rate of apoptosis of CD4+ $\mathrm{T}$ lymphocytes and accessory cells in lymphoid tissues, Proc. Natl. Acad. Sci. USA 93 (1996), 11 057-11 062.

[2] S.P. Aries, K. Weyrich, B. Schaaf, F. Hansen, R.H. Dennin and K. Dalhoff, Early T-cell apoptosis and Fas expression during antiretroviral therapy in individuals infected with human immunodeficiency virus-1, Scand. J. Immunol. 48 (1998), 86-91.

[3] K. Banki, E. Hutter, N.J. Gonchoroff and A. Perl, Molecular ordering in HIV-indiced apoptosis. Oxidative stress, activation of caspases, and cell survival are regulated by transaldolase, J. Biol. Chem. 273 (1998), 11944-11953.

[4] T. Bohler, J. Walcher, G. Holzl-Wenig, M. Geiss, B. Buchholz, R. Linde, K.M. Debatin, Early effects of antiretroviral combination therapy on activation, apoptosis and regeneration of T cells in HIV-1-infected children and adolescents, AIDS $\mathbf{1 3}$ (1999), 779-789.

[5] F. Boudet, H. Lecoeur and M.L. Gougeon, Apoptosis associated with ex vivo down-regulation of $\mathrm{Bcl}-2$ and up-regulation of Fas in potential cytotoxic CD8+ T lymphocytes during HIV infection, J. Immunol. 156 (1996), 2282-2293.

[6] M. Carbonari, M. Cibati, M. Cherchi, D. Sbarigia, A.M. Pesce, L. Dell'Anna, A. Modica and M. Fiorilli, Detection and characterization of apoptotic peripheral blood lymphocytes in human immunodeficiency virus infection and cancer chemotherapy by a novel flow immunocytometric method, Blood 83 (1994), 1268-1277.

[7] A. Cayota, F. Vuillier, G. Gonzales and G. Dighiero, In vitro antioxidant treatment recovers proliferative responses of anergic CD4+ lymphocytes from human immunodeficiency virusinfected individuals, Blood 87 (1996), 4746-4753.

[8] D.R. Clark, N.M. Ampel, C.A. Hallet, V.R. Yedavalli, N. Ahmad and D. DeLuca, Peripheral blood human immunodeficiency virus type 1-infected patients displays diminished $\mathrm{T}$ cell generation capacity, J. Infect. Dis. 176 (1997), 649-654.
[9] M.F. Cotton, D.N. Ikle, E.L. Rapaport, S. Marschner, P.O. Tseng, R. Kurrle and T.H. Finkel, Apoptosis of CD4+ and CD8+ T cells isolated immediately ex vivo correlates with disease severity in human immunodeficiency virus type 1 infection, Pediatr. Res. 42 (1997), 656-664.

[10] A. Favier, C. Sappey, P. Leclerc, P. Faure and M. Micoud, Antioxidant status and lipid peroxidation in patients infected with HIV, Chem. Biol. Interact. 91 (1994), 180-195.

[11] S. Fleury, R.J. De Boer, G.P. Rizzardi, K.C. Wolthers, S.A. Otto, C.C. Welbon, C. Graziosi, C. Knabenhans, H. Soudeyns, P.A. Bart, S. Gallant, J.M. Corpataux, M. Gillet, P. Meylan, P. Schnyder, J.Y. Meuwly, W. Spreen, M.P. Glauser, F. Miedema and G. Pantaleo, Limited CD4+ T-cell renewal in early HIV-1 infection: effect of highly active antiretroviral therapy, Nat. Med. 4 (1998), 794-801.

[12] M.L. Gougeon, Does apoptosis contribute to CD4 T cell depletion in human immunodeficiency virus infection?, Cell Death and Differentiation 2 (1995), 1-8.

[13] M.L. Gougeon, G. Dadaglio, S. Garcia, H. Müller-Alouf, R. Roue and L. Montagnier, Is a dominant superantigen involved in AIDS pathogenesis, Lancet 342 (1993), 50-51.

[14] M.L. Gougeon, H. Lecoeur, A. Dulioust, M.G. Enouf, M. Crouvoisier, C. Goujard, T. Debord and L. Montagnier, Programmed cell death in peripheral lymphocytes from HIV-infected persons: increased susceptibility to apoptosis of CD4 and CD8 T cells correlates with lymphocyte activation and with disease progression, J. Immunol. 156 (1996), 3509-3520.

[15] M.L. Gougeon and L. Montagnier, Apoptosis in peripheral $\mathrm{T}$ lymphocytes during HIV-infection: influence of superantigens and correlation with AIDS pathogenesis, in: Apoptosis II: The Molecular Basis of Apoptosis in Disease, D. Tomei and F. Cope eds, Cold Spring Harbor Laboratory Press, New York, 1984, pp. 5-12.

[16] R. Graber, J.C. Farine and G.A. Losa, Calcium dobesilate protects human peripheral blood mononuclear cells from oxidation and apoptosis, Apoptosis 3 (1998), 41-49.

[17] R. Graber and G.A. Losa, Changes in the activities of signal transduction and transport membrane enzymes in CEM lymphoblastoid cells by glucocorticoid-induced apoptosis, Anal. Cell. Pathol. 8 (1995), 159-176.

[18] H.C. Greenspan and O. Arouma, Could oxidative stress initiate programmed cell death in HIV infection? A role for plant derived metabolites having synergistic antioxidant activity, Chem. Biol. Interact. 94 (1995), 187-197.

[19] M. Hellerstein, M.B. Hanley, D. Cesar, S. Siler, C. Papageorgopoulus, F. Wieder, D. Schmidt, R. Hoh, R. Neese, D. Macallan, S. Deeks and J.M. McCune, Directly measured kinetics of circulating T lymphocytes in normal and HIV-1infected humans, Nat. Med. 5 (1999), 83-89.

[20] G. Herbein, U. Mahlknecht, F. Batliwalla, P. Gregersen, T. Pappas, J. Butler, W.A. O'Brien and E.Verdin, Apoptosis of CD8+ $T$ cells is mediated by macrophages through interaction of HIV gp120 with chemokine receptor CXCR4, Nature 395 (1998), 189-194.

[21] L.A. Herzenberg, S.C. De Rosa, J.G. Dubs, M. Roederer, M.T. Anderson, S.W. Ela, S.C. Derensinski and L.A. Herzenberg, Glutathione deficiency is associated with impaired survival in HIV disease, Proc. Natl. Acad. Sci. USA 94 (1997), 1967-1972. 
[22] N. Israel and M.A. Gougerot-Pocidalo, Oxidative stress in human immunodeficiency virus infection, Cell. Mol. Life Sci. $\mathbf{5 3}$ (1997), 864-870.

[23] A. Klein, L. Mercure, P. Gordon, B. Bruser, S. Ramcharitar, A. Malki and M.A. Wainberg, The effect of HIV-1 infection on the lipid fatty acid content in the membrane of cultured lymphocytes, AIDS 4 (1990), 865-867.

[24] A. Lanzavecchia, E. Roosnek, T. Gregory, P. Berman and S. Abrignani, T cells can present antigen such as HIV gp 120 targeted to their own surface molecules, Nature 334 (1988), 530-532.

[25] L. Leoni and G.A. Losa, Changes in membrane enzymes and glycosphingolipids in lymphocytes from HIV-1-infected and noninfected intravenous drug abusers, J. AIDS Hum. Retrovirology 11 (1996), 188-197.

[26] T.J. Liegler, W. Yonemoto, T. Elbeik, E. Vittinghoff, S.P. Buchbinder and W.C. Greene, Diminished spontaneous apoptosis in lymphocytes from human immunodeficiency virus-infected long-term nonprogressors, J. Infect. Dis. 178 (1998), 669-679.

[27] G.A. Losa, Enzymatic imbalance in peripheral blood mononuclear cells from individuals with anti-HIV antibodies, Clin. Biochem. 22 (1989), 321-328.

[28] M. Mahalingam, A. Pozniak, T.J. McManus, D. Vergani and M. Peakman, Cell cycling in HIV infection: analysis of in vivo activated lymphocytes, Clin. Exp. Immunol. 102 (1995), 481486.

[29] W. Malorni, R. Rivabene, B.M. Lucia, R. Ferrara, A.M. Mazzone, R. Cauda and R. Paganelli, The role of oxidative imbalance in progression to AIDS: effect of the thiol supplier Nacetylcysteine, AIDS Res. Hum. Retroviruses 14 (1998), 15891596.

[30] S. Martin, C.P.M. Reutelingsperger,A.J. McGahon, J.A. Rader, R.C. van Schie, D.M. LaFace and D.R. Green, Early redistribution of plasma membrane phosphatidyl-serine is a general feature of apoptosis regardless of the initiating stimulus: inhibition by overexpression of Bcl-2 and Abl, J. Exp. Med. 182 (1995), 1545-1556

[31] D.P. Merrill, J. Martinez-Picado, C. Tremblay, P.E. Sax, S.L. Boswell, J.T. Wong, R.T. D'Aquila, B.D. Walker and M.S. Hirsch, Improved CD4 lymphocyte outgrowth in response to effective antiretroviral therapy, J. Infect. Dis. 179 (1999), 345-351.

[32] J. Mirkovitch, The role of chromatin in HIV-1 transcriptional regulation, Immunobiol. 198 (1997), 279-290.

[33] J.L. Murray, K.C. Loftin and C.G. Munn, Elevated adenosine deaminase and purine nucleoside phosphorylase activity in peripheral blood null lymphocytes from patients with acquired immune deficiency syndrome, Blood 65 (1985), 1318-1324.

[34] J.L. Murray, J.M. Reuben and C.G. Munn, Decreased $5^{\prime}$-nucleotidase activity in lymphocytes from asymptomatic sexually active homosexual men and patients with acquired immune deficiency syndrome, Blood 64 (1984), 1016-1021.

[35] G.W. Pace and C.D. Leaf, The role of oxidative stress in HIV disease, Free Radic. Biol. Med. 19 (1995), 523-528.

[36] G. Pan, T. Zhou, W. Radding, M.S. Saag, J.D. Mountz and J.M. McDonald, Calmodulin antagonists inhibit apoptosis of CD4+ T-cells from patients with AIDS, Immunopharmacology 40 (1998), 91-103.
[37] G. Pantaleo, Unraveling the strands of HIV's web, Nat. Med. 5 (1999), 27-28

[38] P.X. Petit, H. Lecoeur, E. Zorn, C. Dauguet, B. Mignotte and M.L. Gougeon, Alterations in mitochondrial structure and function are early events of dexamethasone-induced thymocyte apoptosis, J. Cell. Biol. 130 (1995), 157-167.

[39] G. Piedimonte, D. Guetard, M. Mahnani, D. Corsi, I. Picerno, P. Spataro, L. Kramer, M. Montroni, G. Silvestri, J.F. Torres Roca and L. Montagnier, Oxidative protein damage and degradation in lymphocytes from patients infected with human immunodeficiency virus, J. Infect. Dis. 176 (1997), 655-664.

[40] M. Pirmohamed, D. Williams, M.D. Tingle, M. Barry, S.H. Khoo, C. O’Mahony, E.G. Wilkins, A.M. Breckenridge and B.K. Park, Intracellular glutathione in the peripheral blood cells of HIV-infected patients: failure to show a deficiency, AIDS 10 (1996), 501-507.

[41] C. Rabaud, H. Tronel, S. Fremont, T. May, P. Canton and J.P. Nicolas, Free radicals and HIV infection, Ann. Biol. Clin. 55 (1997), 565-571.

[42] M. Roederer, S.W. Ela, F.J. Staal, and L.A. Herzenberg, N-acetylcysteine: a new approach to anti-HIV therapy, AIDS Res. Hum. Retroviruses 8 (1992), 209-217.

[43] D. Romero-Alvira and E. Roche, The keys of oxidative stress in acquired immune deficiency syndrome apoptosis, Med. Hypotheses 51 (1998), 169-173.

[44] A. Salazar-Gonzales, Reduced ecto-5'-nucleotidase activity and enhanced OKT10 and HLA-DR expression on CD8 (T suppressor/cytotoxic) lymphocytes in the acquired immune deficiency syndrome: evidence of CD8 cell immaturity, J. Immunol. 135 (1985), 1778-1783.

[45] A. Samuelsson, C. Brostrom, N. van Dijk, A. Sonnerborg and F. Chiodi, Apoptosis of CD4+ and CD19+ cells during human immunodeficiency virus type 1 infection. Correlation with clinical progression, viral load, and loss of humoral immunity, Virology 238 (1997), 180-188.

[46] T.K. Smith and A. Meister, Active deglycosylated mammalian $\gamma$-glutamyl transpeptidase, FASEB J. 8 (1994), 661-664.

[47] F.J. Staal, Glutathione and HIV infection: reduced reduced, or increased oxidized?, Eur. J. Clin. Invest. 28 (1998), 194-196.

[48] A.J. van der Ven, H.J. Blom, W. Peters, L.E. Jacobs, T.J. Verver, P.P. Koopmans, P. Denacker and J.W. van der Meer, Glutathione homeostasis is disturbed in CD4-positive lymphocytes of HIV-seropositive individuals, Eur. J. Clin. Invest. 28 (1998), 187-193.

[49] S.L. Walmsley, L.M. Winn, M.L. Harrison, J.P. Uetrecht and P.G. Wells, Oxidative stress and thiol depletion in plasma and peripheral blood lymphocytes from HIV-infected patients: toxicological and pathological implications, AIDS 11 (1997), 1689-1697.

[50] Z.Q. Zhang, D.W. Notermans, G. Sedgewick, W. Cavert, S. Wietgrefe, M. Zupancic, K. Gebhard, K. Henry, L. Boies, Z. Chen, M. Jenkins, R. Mills, H. McDade, C. Goodwin, C.M. Schuwirth, S.A. Danner and A.T. Haase, Kinetics of CD4+ T cell repopulation of lymphoid tissues after treatment of HIV-1 infection, Proc. Natl. Acad. Sci. USA 95 (1998), 1154-1159. 


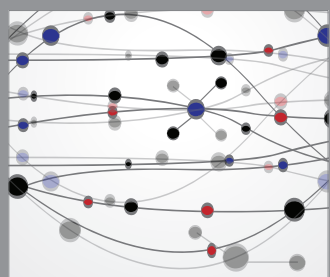

The Scientific World Journal
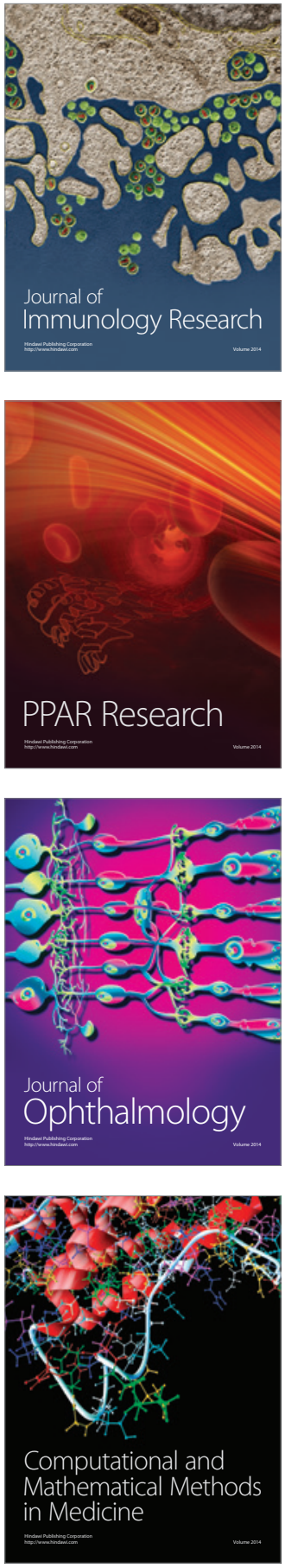

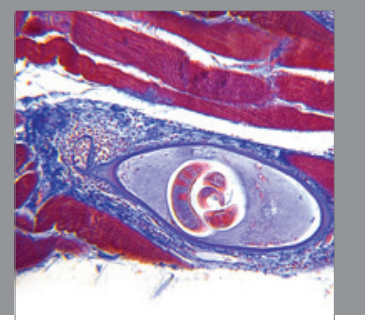

Gastroenterology

Research and Practice
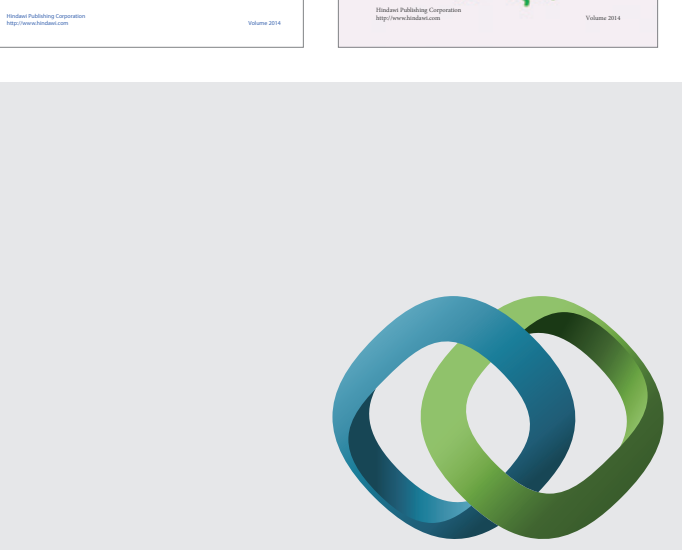

\section{Hindawi}

Submit your manuscripts at

http://www.hindawi.com
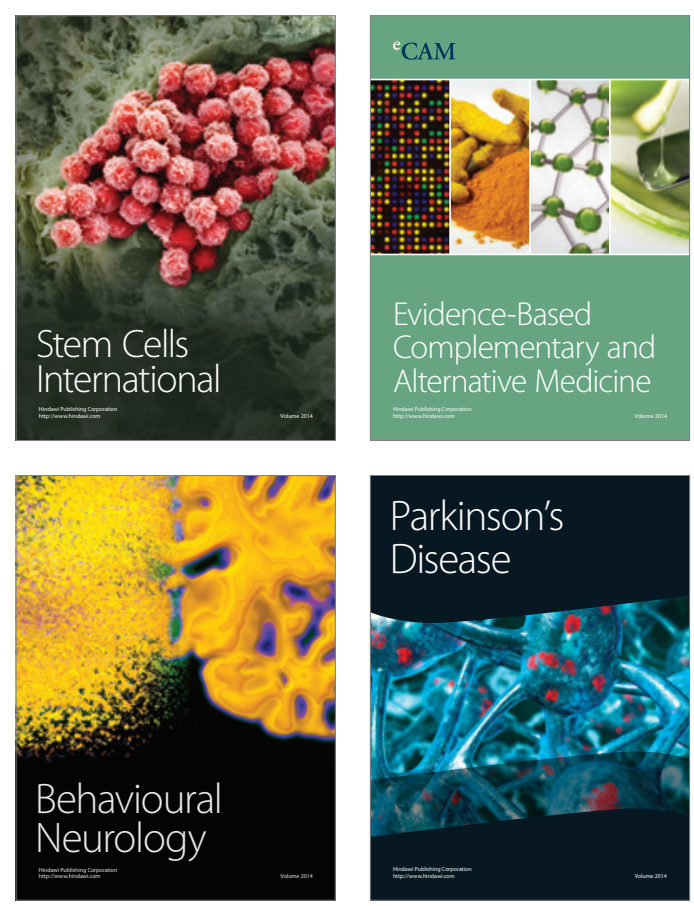

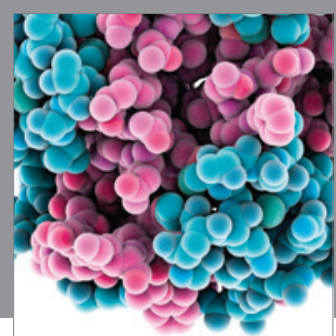

Journal of
Diabetes Research

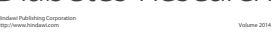

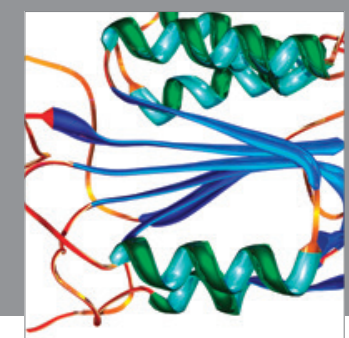

Disease Markers
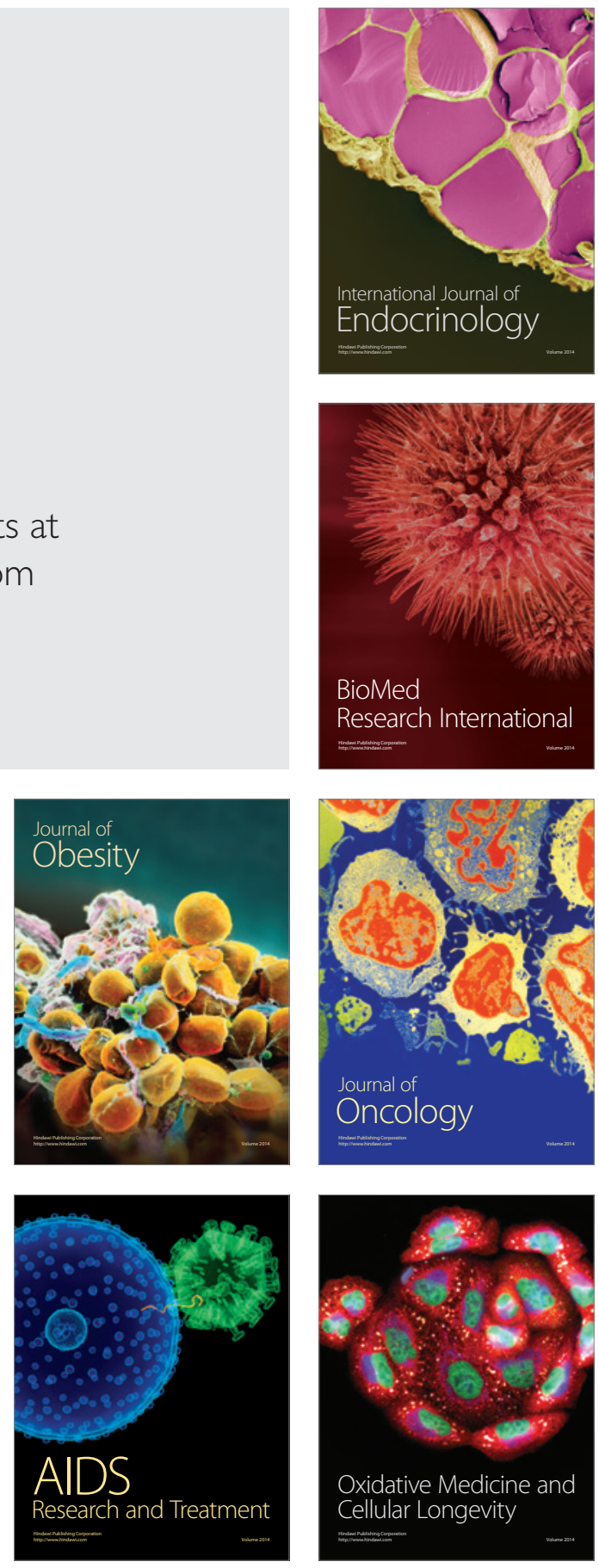